Jurnal Indonesia Sosial Teknologi: p-ISSN: 2723 - 6609

e-ISSN : 2745-5254

Vol. 2, No. 11 November 2021

\title{
MONITORING DAN KENDALI KONVEYOR PENYORTIR BARANG BERDASARKAN WARNA RGB BERBASIS SUPERVISORY CONTROL AND DATA ACQUISITION
}

\author{
Idries Syach ${ }^{1}$, Yumna Salma Azzahra ${ }^{2}$, Sandra Rayhan Seftia ${ }^{3}$. \\ Jurusan Teknik Elektro, Politeknik Negeri Bandung, Indonesia ${ }^{1,2,3}$ \\ Email : idries.syach.tele419@polban.ac.id ${ }^{1}$, yumna.salma.tele418@ polban.ac.id ${ }^{2}$, \\ sandra.rayhan.tele420@polban.ac.id ${ }^{3}$
}

\begin{abstract}
Abstrak
Robot penyortir barang berdasarkan warna RGB adalah sebuah implementasi monitoring dan kendali konveyor yang terdiri dari sebuah konveyor, lengan penyortir serta sensor pendeteksi warna objek yang dilengkapi oleh pengontrolan berbasis SCADA (Supervisory Control And Data Acquistion). Pusat pengontrolan dalam perancangan ini diolah oleh mikrokontroler Arduino Mega Pro 2560 dan Sensor TCS3200 untuk mengubah warna menjadi frekuensi sebagai input. Sensor tersebut akan mendeteksi warna objek yang akan menjadi input Arduino Mega Pro 2560 kemudian memerintahkan motor servo untuk memilah warna yang telah terdeteksi. Kemudian untuk menggerakkan konveyor dibutuhkan driver motor L298N yang dihubungkan dengan Arduino dan mendapatkan input PWM agar dapat diatur kecepatannya. Untuk dilakukan proses pemantauan serta pengendalian jarak jauh dapat menggunakan HMI yang berbasis SCADA sehingga keberjalanan plant dapat dipantau. Terdapat berbagai fitur yang diaplikasikan pada HMI seperti sistem keamanan, pengaturan hak pengguna, penyimpanan data ke database serta alarm dan maintenance. Ketika sistem ini mengalami kerusakan, indicator alarm pada tampilan pada layer HMI akan menyala merah berkedip serta terdapat bunyi alarm peringatan untuk memberitahu pengguna agar plant dapat segera diperbaiki. Sehingga proses penyortiran berbasis SCADA ini dapat bekerja dengan baik.
\end{abstract}

Kata kunci: RGB; SCADA; Arduino Mega Pro 2560; HMI; TCS3200.

\section{Abstract}

The goods sorter robot based on RGB color is a conveyor monitoring and control implementation consisting of a conveyor, sorting arm and object color detection sensor equipped with SCADA (Supervisory Control And Data Acquistion) based control. The control center in this design is processed by the Arduino Mega Pro 2560 microcontroller and the TCS3200 sensor to change color into frequency as input. The sensor will detect the color of the object that will be input to the Arduino Mega Pro 2560 and then instruct the servo motor to sort out the detected colors. Then to drive the conveyor, an L298N motor driver is needed which is connected to Arduino and gets PWM input so that the speed can be adjusted. To carry out the monitoring and remote control process, you can use a SCADA-based HMI so that the operation of the plant can be monitored. There are various features that are applied to HMI such as security systems, user rights settings, data storage to databases as well as 
Idries Syach, Yumna Salma Azzahra, dan Sandra Rayhan Seftia

alarms and maintenance. When this system is damaged, the alarm indicator on the display on the HMI layer will flash red flashing and there will be a warning alarm sound to notify the user so that the plant can be repaired immediately. So that this SCADA-based sorting process can work well.

Keyword: RGB; SCADA; Arduino Mega Pro 2560; HMI; TCS3200.

\section{Pendahuluan}

Seiring dengan perkembangannya teknologi industri, sudah banyak yang mengaplikasikan sebuah sistem otomatisasi menggunakan mesin robot untuk meminimalisir penggunaan tenaga kerja manusia. Hal ini dikarenakan terdapat banyak keuntungan diantaranya hanya membutuhkan waktu yang relatif singkat, akan mendapatkan hasil yang akurat karena sudah tidak lagi menggunakan tenaga kerja manusia yang memungkinkan terdapat human error, dan perusahaan tidak perlu mengeluarkan terlalu banyak untuk membayar gaji pegawai yang bekerja pada industri tersebut (Larasati, 2018).

Banyak proses pada industri yang dapat menggunakan sistem otomatisasi ini, salah satunya adalah pada proses penyortir barang berdasarkan warna RGB menggunakan mikrokontroler Arduino mega 2560 yang memiliki tujuan untuk memisahkan barang berdasarkan warna merah, hijau, dan biru (Steveen, 2018). Proses ini menggunakan konveyor untuk memindahkan barangnya serta motor servo sebagai lengan untuk menyortir ke tempat yang sudah disediakan. Dengan demikian proses penyortiran pun akan berlangsung secara efektif, efisien, dan akurat (Rasyid, 2018).

Agar proses yang dilakukan oleh robot tersebut berjalan dengan optimal, maka diperlukan dengan adanya monitoring serta pengendalian yang dapat diakses lewat HMI (Human Machine Interface) oleh manusia (Setianto, 2018). Dan dalam perancangan ini menggunakan HMI SCADA. Sistem ini mencakup transfer data antara pusat SCADA komputer host dan sejumlah Unit Terminal Jarak Jauh (RTU) dan/atau dapat Diprogram Logic Controllers (PLCs), dan host pusat dan terminal operator (Rif'an, 2012). Sistem SCADA mengumpulkan informasi (seperti di mana kebocoran pada pipa telah terjadi), transfer informasi kembali ke situs pusat, lalu memberi tahu stasiun asal bahwa ada kebocoran terjadi, melakukan analisis dan pengendalian yang diperlukan, seperti menentukan apakah kebocoran itu kritis, dan menampilkan informasi secara logis dan terorganisir. Sistem ini dapat relatif sederhana, seperti yang memantau kondisi lingkungan kecil gedung perkantoran, atau yang sangat kompleks, seperti sistem yang memantau semua aktivitas di pembangkit listrik tenaga nuklir atau aktivitas sistem air kota (Adams, 2004).

Pada penelitian oleh (Fikri, Susana, \& Nataliana, 2014), perancangan sistem pengepakan dan penyortir barang menggunakan PLC sebagai pusat pengendali. Dan dalam penelitian ini, menggunakan komponen pusat pengendali Arduino Mega Pro 2560 karena memiliki kemudahan dalam melakukan perancangan dan pemrograman. Kemudian dalam pendeteksian objek yang akan disortir, pada penelitian (Pangestu,

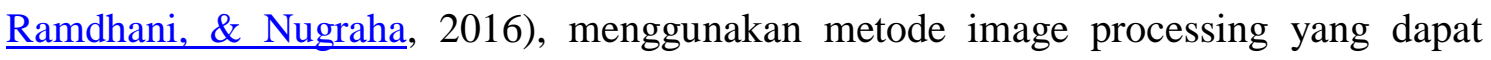


mengekstrak gambar objek dengan menggunakan kamera sehingga objek tersebut dapat dikenali oleh komputer dengan tingkat keberhasilan sebesar 76\%. Sedangkan untuk penelitian ini menggunakan komponen yang cukup sederhana yakni sensor warna TCS3200 yang akan mendeteksi objek (Sari, Handayani, Siregar, \& Isnu, 2018). Memang sama hal nya dari penelitian tersebut dengan penelitian penulis bawah pendeteksian berdasarkan warn aini sangat dipengaruhi oleh kondisi cahaya sekitar, maka dari itu sangat diperlukan proses kalibrasi.

\section{Metode Penelitian}

A. Diagram Blok Sistem

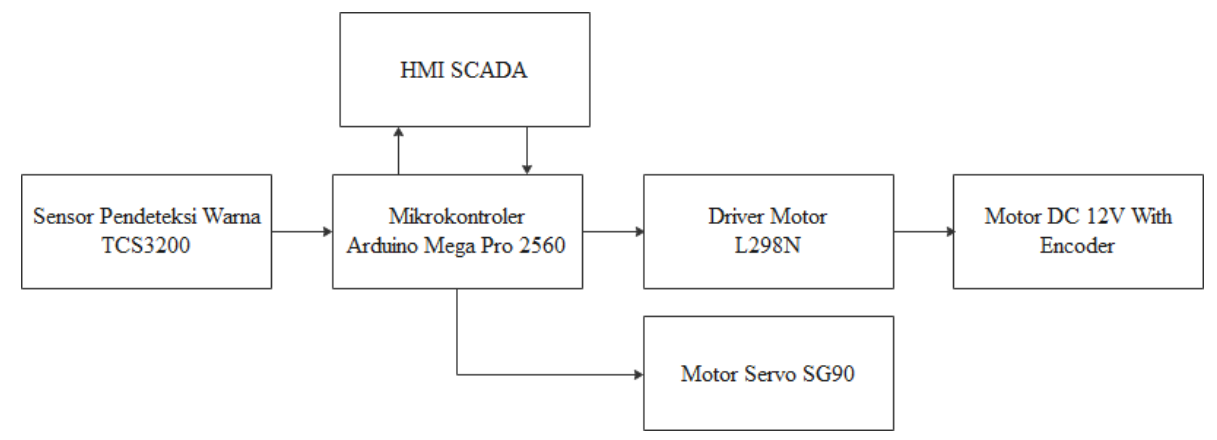

Gambar 1 Diagram blok sistem

Gambar 1 diatas menunjukkan diagram blok sistem yang menggambarkan hubungan antar bagian pada alat ini. Hasil pendeteksian objek oleh sensor warna TCS3200 akan menjadi input Arduino Mega Pro 2560 kemudian memerintahkan motor servo untuk memilah warna yang telah terdeteksi sebelumnya. Kemudian untuk menggerakkan konveyor dengan motor DC 12V dibutuhkan driver motor L298N yang disambung dengan Arduino dan mendapatkan input PWM agar dapat diatur kecepatannya (Husni, N. L., Rasyad, S., Hasan, Y., \& Al Rasyid, 2019). Terdapat sub blok HMI SCADA yang berfungsi sebagai monitoring dan pengendali keseluruhan sistem, sehingga memiliki dua arah panah yang berlawanan.

B. Bagian Utama Sistem

a) HMI SCADA (Supervisory Control And Data Acquisition)

HMI (Human Machine Interface) adalah suatu sistem yang menghubungkan antara mesin dengan pengguna sehingga pengguna dapat melakukan pengawasan maupun pengendalian mesin melewati HMI.

SCADA adalah singkatan dari Supervisory Control and Data Acquisition. Sistem SCADA digunakan untuk memantau dan mengendalikan pabrik atau peralatan di industri. Dalam sistem SCADA ini memiliki bagian-bagian yakni sebagai berikut : 
1. Satu atau lebih perangkat antarmuka data lapangan, biasanya RTU, atau PLC, yang menghubungkan ke perangkat penginderaan lapangan dan switchbox kontrol lokal dan aktuator katup.

2. Sistem komunikasi yang digunakan untuk mentransfer data antar perangkat antarmuka data lapangan dan unit kontrol dan komputer di host pusat SCADA. Sistemnya bisa radio, telepon, kabel, satelit, dll., atau kombinasi dari semuanya.

3. Server atau server komputer host pusat (kadang-kadang disebut SCADA Center, master stasiun, atau Master Terminal Unit (MTU)

4. Kumpulan perangkat lunak standar dan/atau kustom [terkadang disebut Mesin Manusia Perangkat lunak Interface (HMI) atau perangkat lunak Man Machine Interface (MMI)] sistem yang digunakan untuk menyediakan host pusat SCADA dan aplikasi terminal operator, mendukung sistem komunikasi, dan memantau dan mengontrol antarmuka data lapangan yang terletak dari jarak jauh perangkat.

b) Arduino Mega Pro 2560

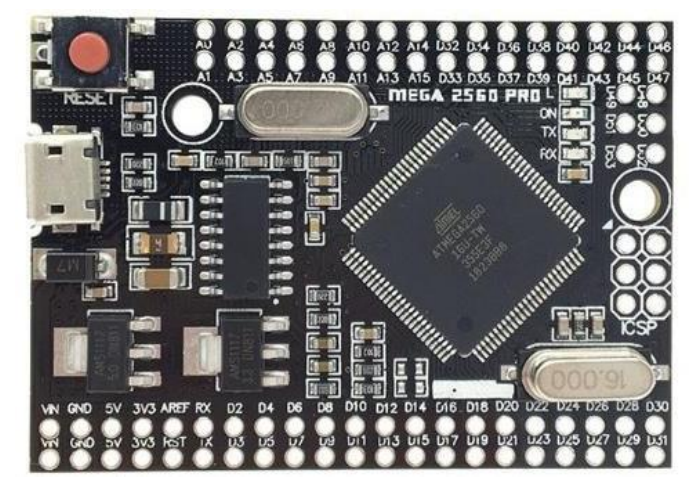

Gambar 2 Board Arduino Mega Pro 2560

Papan Mega Pro Embed CH340G / ATmega2560 didasarkan pada mikrokontroler ATmega2560 dan adaptor USB-UART CH340, sehingga memungkinkan untuk menghubungkan mikrokontroler ke komputer melalui adaptor USB-UART CH340 Memiliki resonator kuarsa berkualitas tinggi 16 MHz. Arus keluaran maksimum pada 5V adalah sekitar $800 \mathrm{~mA}$, sedangkan pada 3.3V sekitar $800 \mathrm{~mA}$. Papan dapat diberi daya langsung melalui konektor Micro USB, atau melalui kontak. Arduino Mega Pro 2560 ini didukung oleh software Arduino IDE untuk melakukan pemrograman, debugging, kompilasi program, dan proses download pada Arduino.

c) Sensor TCS3200 


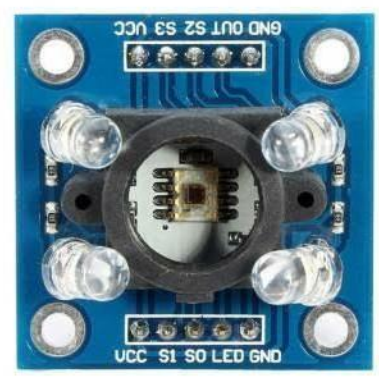

Gambar 3 Sensor TCS3200

TCS3200 merupakan konverter yang diprogram untuk mengubah warna menjadi frekuensi yang tersusun atas konfigurasi silicon photodiode dan konverter arus ke frekuensi dalam IC CMOS monolithic yang tunggal. Keluaran dari sensor ini adalah gelombang kotak (duty cycle 50\%) frekuensi yang berbanding lurus dengan intensitas cahaya (irradiance). Di dalam TCS3200, konverter mengubah warna ke ke frekuensi dengan cara membaca sebuah array $8 \times 8$ photodioda, dimana, 16 photodioda mempunyai penyaring warna biru, 16 photodioda mempunyai penyaring warna merah, 16 photodioda mempunyai penyaring warna hijau dan 16 photodioda untuk warna terang tanpa penyaring.

C. Perancangan Mekanik

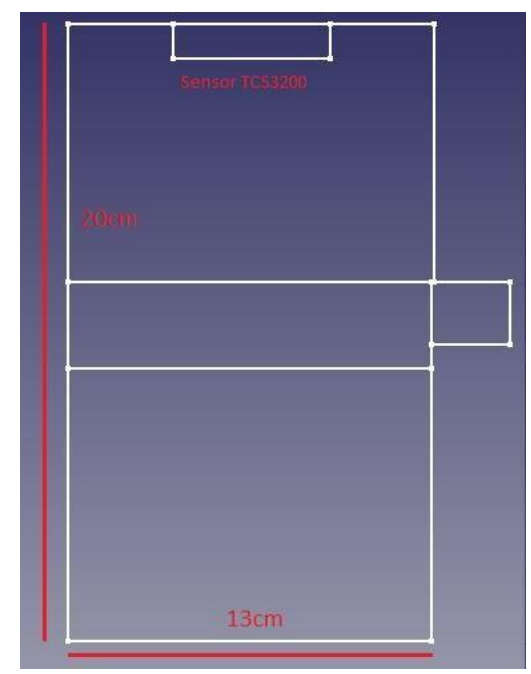

Gambar 4 Desain mekanik tampak depan 


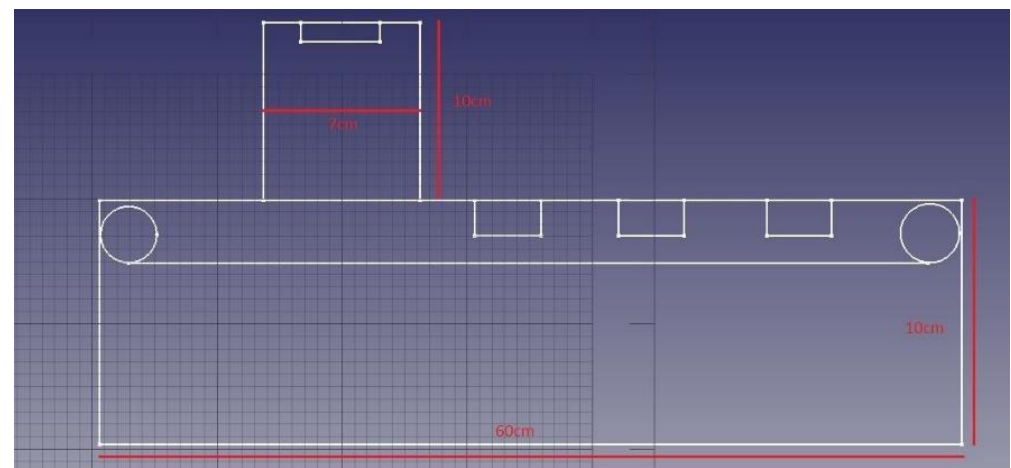

Gambar 5 Desain mekanik tampak samping

Dalam melakukan perancangan mekanik seperti pada gambar diatas, menggunakan bahan dasar kayu dan triplek sebagai bagian mekanik yang paling utama, dengan dimensi Panjang 60 $\mathrm{cm}$, lebar $13 \mathrm{~cm}$, dan tinggi $10 \mathrm{~cm}$.

D. Perancangan Elektronik

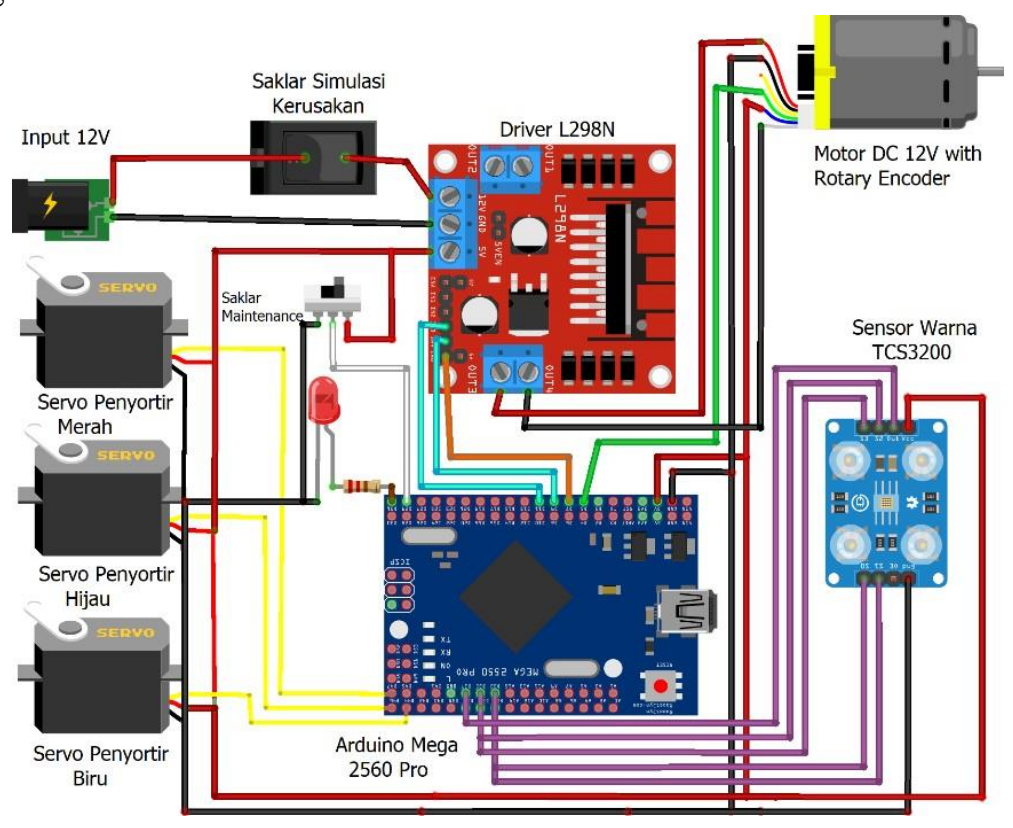

Gambar 6 Rangkaian elektronik

Berikut adalah perancangan elektronik yang dibutuhkan. Sesuai dengan pada gambar 1 diaram blok sistem terdapat sensor TCS3200 yang memberikan input kepada Arduino Mega Pro 2560 yang kemudian akan mengendalikan motor DC $12 \mathrm{~V}$ melalui driver L298N serta tiga buah servo untuk menggerakkan lengan agar barang dapat disortir sesuai dengan warna merah / hijau / biru.

E. Perancangan Sistem SCADA

Berikut merupakan state flow diagram yang dapat menggambarkan secara detail alur dari setiap keadaan bagian pada HMI yang dibuat untuk sistem SCADA yang diterapkan dalam pembuatan alat ini. 


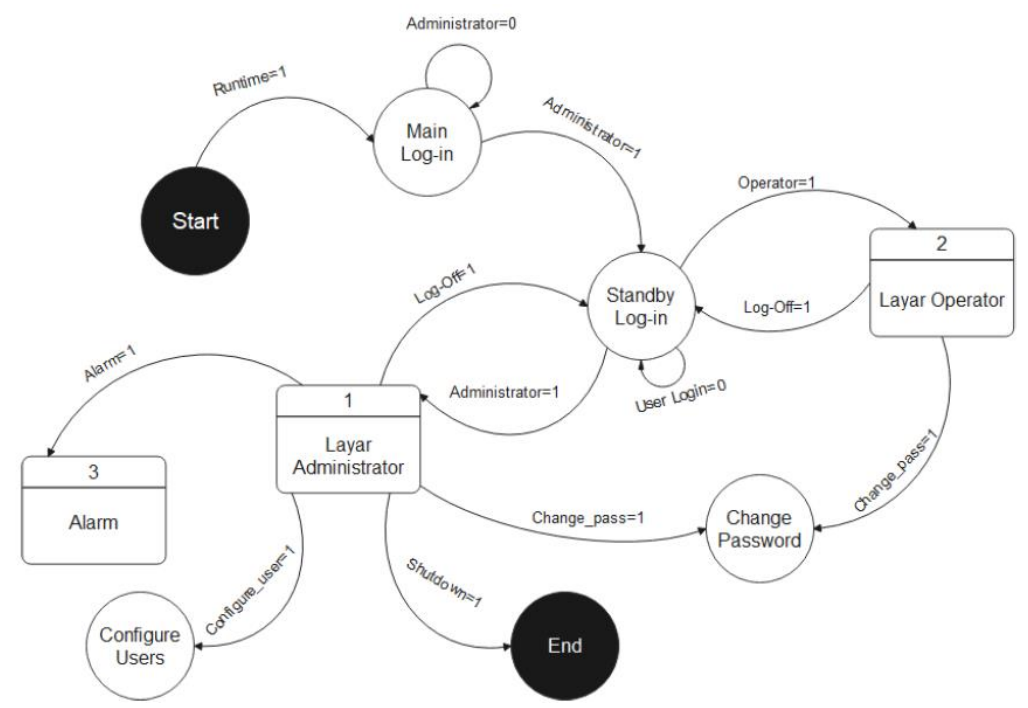

Gambar 7 State flow diagram keseluruhan sistem

Selanjutnya, dalam merancang sistem SCADA, diperlukan sebuah diagram yang dapat menggambarkan hubungan antar bagian-bagian pada komponen yang menysunnya. Berikut digambarkan berupa loop diagram untuk bagian motor konveyor, penyortir barang oleh motor servo, dan pendeteksi warna oleh sensor warna TCS3200.

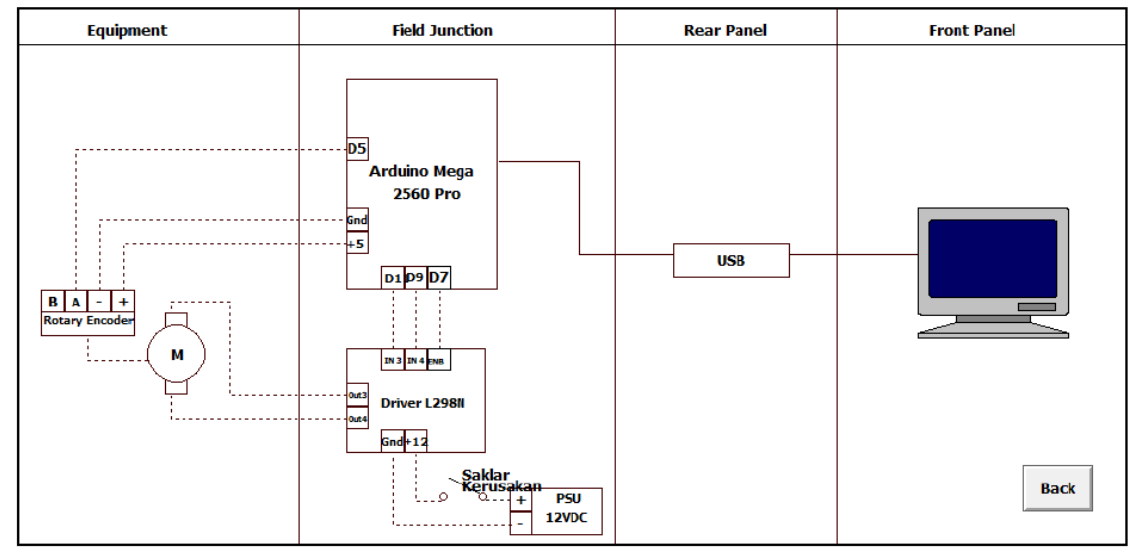

Gambar 8 Loop diagram motor konveyor 
Idries Syach, Yumna Salma Azzahra, dan Sandra Rayhan Seftia

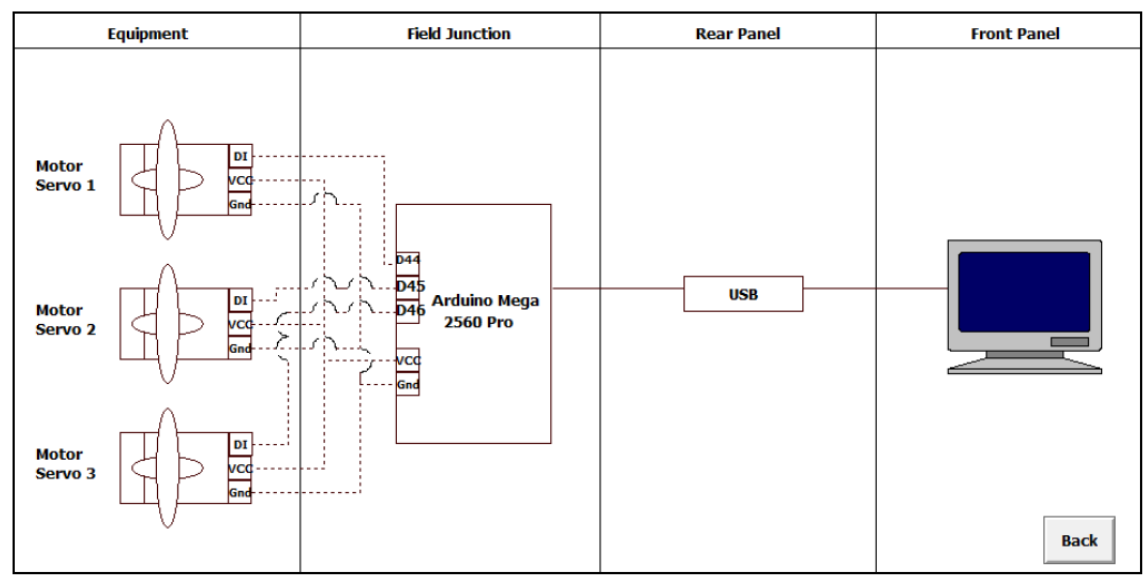

Gambar 9 Loop diagram penyortir

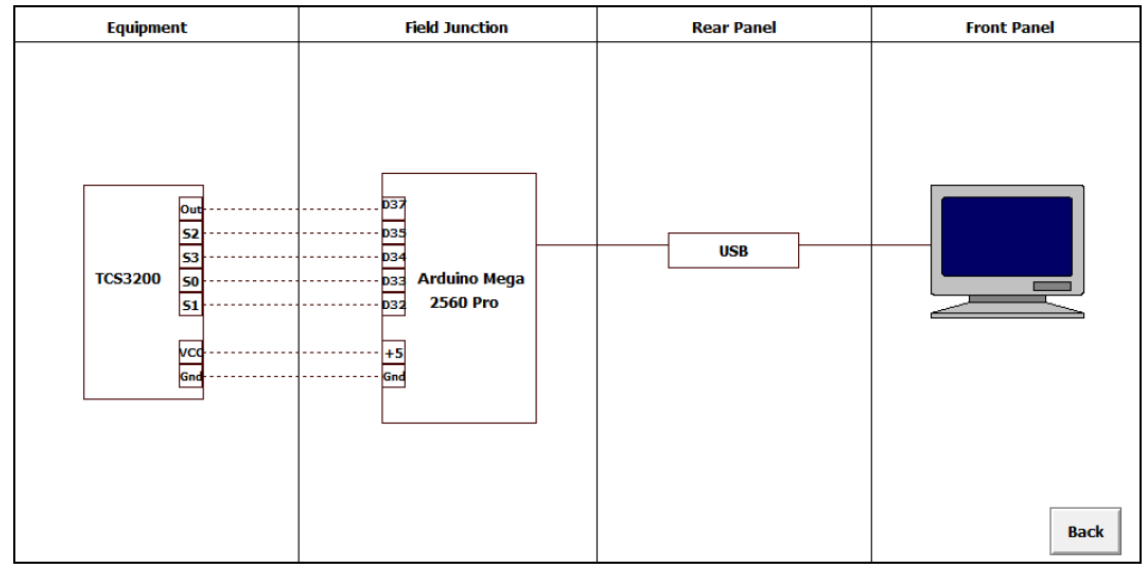

Gambar 10 Loop diagram pendeteksi warna

\section{Hasil dan Pembahasan}

A. Realisasi Perancangan

a) Realisasi Mekanik

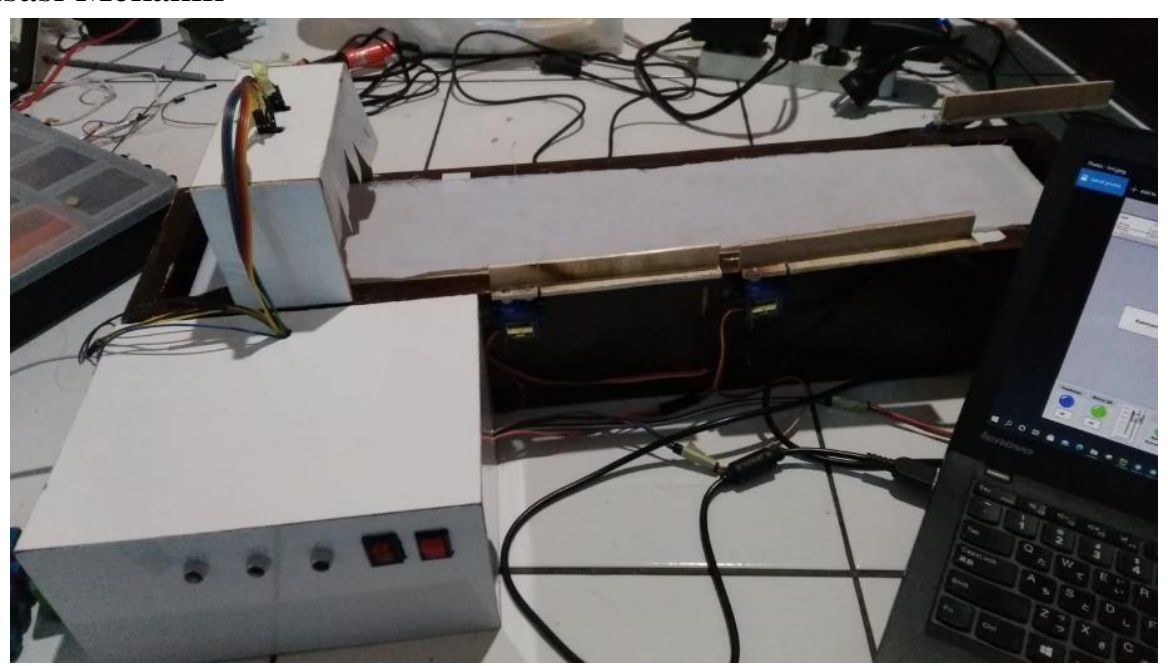

Gambar 11 Realisasi mekanik 
Realisasi mekanik yang telah dibuat memiliki dimensi konveyor Panjang 60cm, lebar $20 \mathrm{~cm}$, dan tinggi $10 \mathrm{~cm}$. Konveyor tersebut dilengkapi dengan tiga buah motor servo yang memiliki jarak masing- masing $10 \mathrm{~cm}$ agar saat proses penyortiran barang tidak mengganggu bagian lainnya. Kemudian terdapat kotak kontrol berwarna putih yang berfungsi sebagai tempat integrasi antar komponen elektronik.

b) Realisasi HMI

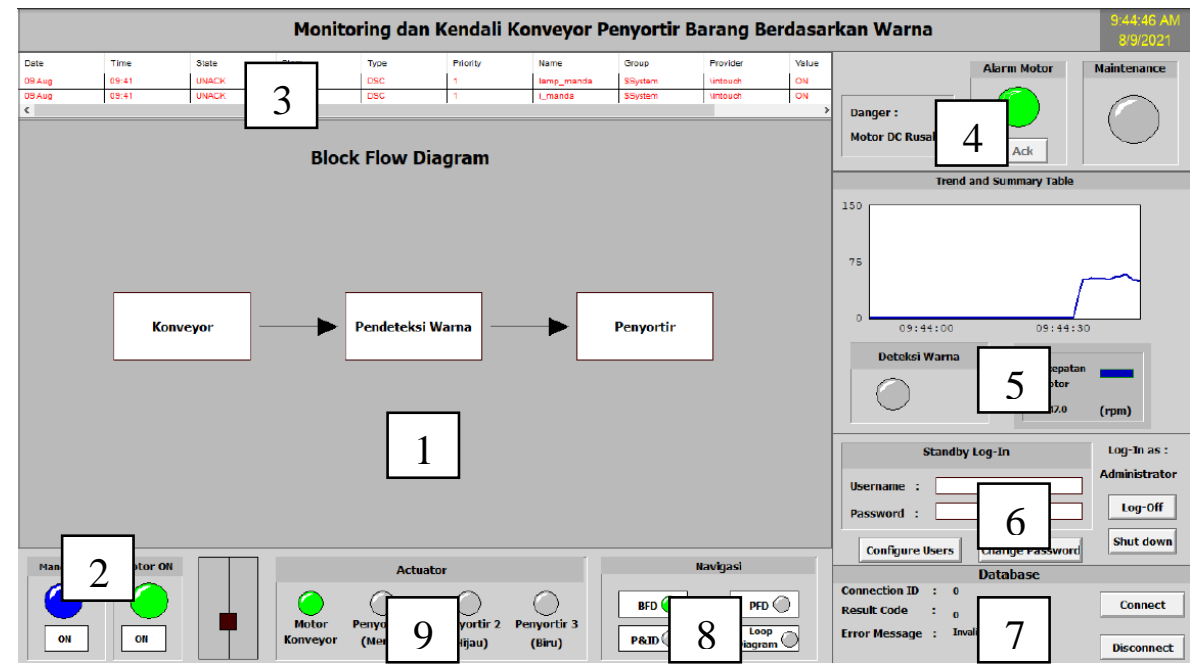

Gambar 12 Realisasi HMI SCADA

Halaman HMI yang direalisasikan memiliki bagian-bagian sebagai berikut :

1. Display diagram perancangan seperti BFD (Blok Flow Diagram), PFD (Process Flow Diagram), P\&ID (Piping \& Instrumentation Diagram), dan Loop Diagram.

2. Panel kontrol. Yang terdiri dari tombol mandatory, tombol untuk mengaktifkan motor DC $12 \mathrm{~V}$ dan slider untuk mengatur kecepatan.

3. Tabel Ack Alarm. Tabel ini akan menunjukkan history daftar alarm yang sudah di Ack ketika alarm menyala.

4. Panel alarm dan maintenance. Terdapat indikator alarm serta maintenance agar operator dapat mengetahui keadaan alat dilapangan.

5. Trend dan summary table. Pada bagian ini akan menampilkan grafik berupa perubahan kecepatan serta tabel keterangan.

6. Stanby login. Pada bagian ini berisikan akses untuk menginput data user serta password serta melakukan log-off maupun shutdown HMI.

7. Database. Laman ini akan terdapat tombol connect dan disconnect ke database yang berfungsi untuk memasukkan data ke database maupun memutuskannya. 
8. Navigasi. Pada bagian navigasi ini, akan terdapat beberapa tombol untuk menampilkan beberapa diagram yang akan ditampilkan seperti pada bagian 1.

9. Keterangan aktuator. Untuk bagian keterangan aktuator, akan menampilkan berupa indikator aktuator yang digunakan yakni motor DC $12 \mathrm{~V}$ untuk konveyor dan tiga buah motor servo untuk memilah barang.

B. Analisa HMI SCADA

a) Keamanan

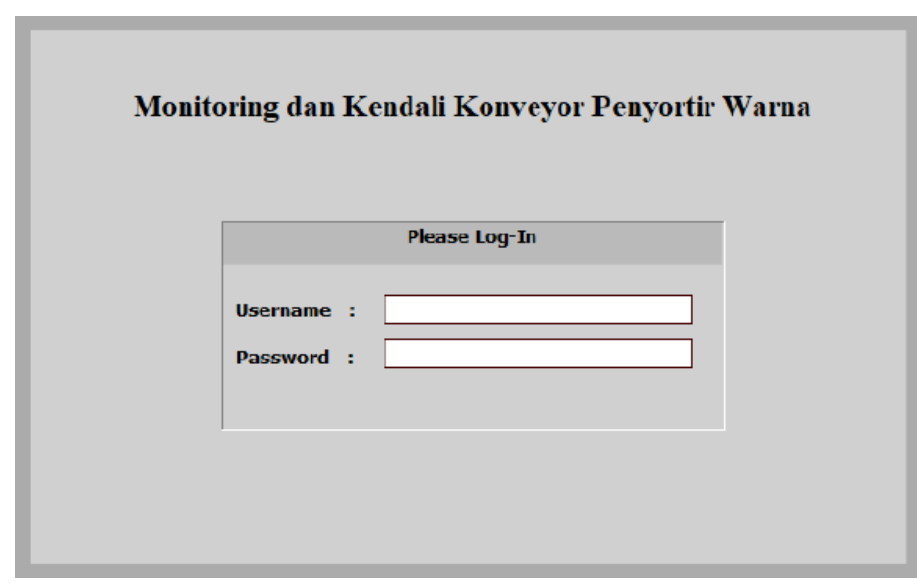

Gambar 13 Halaman login

Pada halaman login ini digunakan pengguna untuk masuk ke halaman selanjutnya dan dapat mengakses fitur-fitur yang ada di HMI SCADA ini seperti pada gambar 4.

b) Aturan pengguna

Terdapat dua pengguna yang dapat masuk kedalam HMI yakni sebagai operator dan sebagai administrator. Masing-masing memiliki hak akses yang berbeda sesuai dengan perancangan yang dilakukan sebelumnya. Berikut adalah perbedaan tampilan HMI untuk pengguna operator dan administrator. 


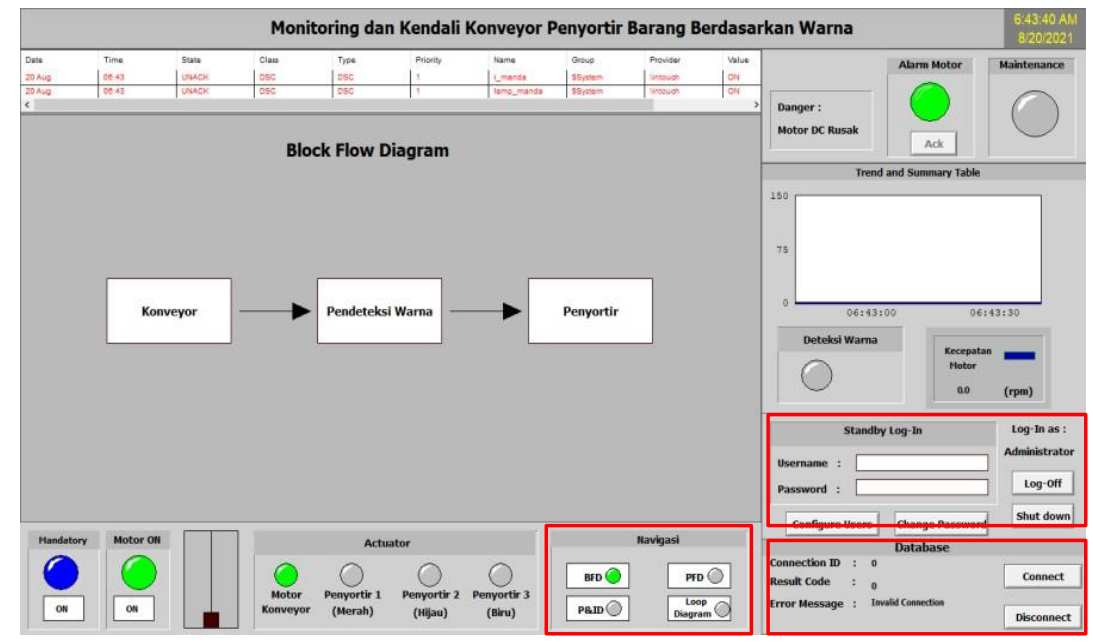

Gambar 14 Halaman administrator

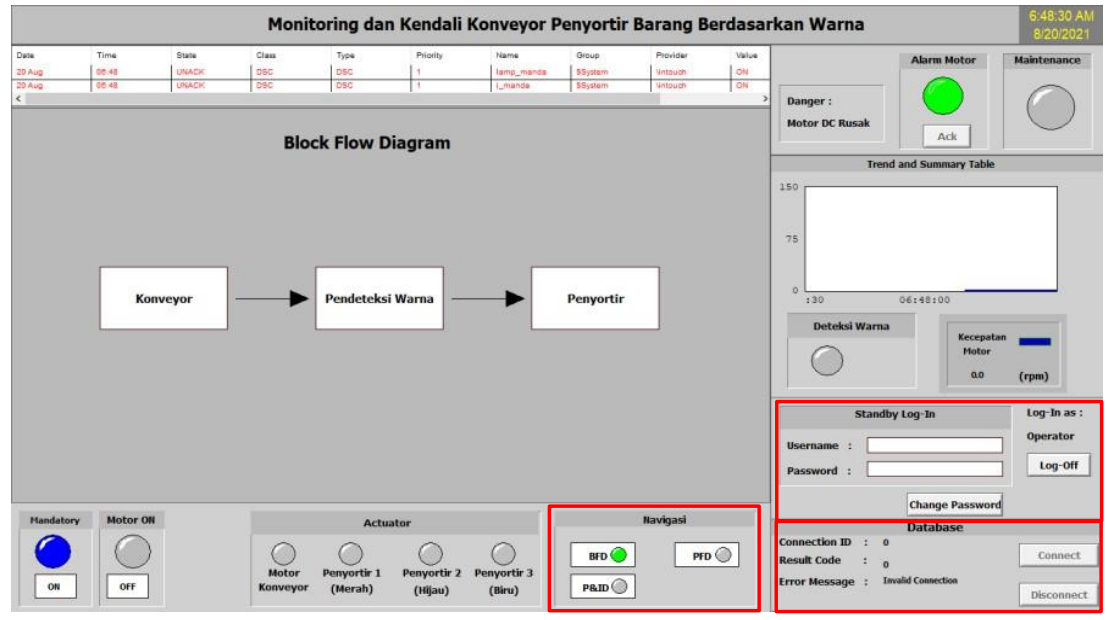

Gambar 15 Halaman operator

Pada perbedaan gambar diatas, terdapat fitur-fitur yang tidak bisa hanya bisa diakses oleh administrator dan tidak bisa diakses oleh operator yakni tombol shutdown, tombol configure users, tombol database dan tombol loop diagram.

c) Database 
Idries Syach, Yumna Salma Azzahra, dan Sandra Rayhan Seftia

\begin{tabular}{|c|c|c|c|c|}
\hline \multicolumn{5}{|c|}{ Tabel_pm X } \\
\hline Nomor & Waktu & - Kecepatan & Warna & $=$ \\
\hline 156 & 7:16:14 PM & 45 & Merah & \\
\hline 157 & 7:16:15 PM & 48 & Hijau & \\
\hline 158 & 7:16:16 PM & 50 & Hijau & \\
\hline 159 & 7:16:17 PM & 48 & Biru & \\
\hline 160 & 7:16:18 PM & 49 & Hijau & \\
\hline 161 & 7:16:19 PM & 50 & Hijau & \\
\hline 162 & 7:16:20 PM & 53 & Hijau & \\
\hline 163 & 7:16:21 PM & 53 & Hijau & \\
\hline 164 & 7:16:22 PM & 32 & Hijau & \\
\hline 165 & 7:16:23 PM & 10 & Biru & \\
\hline 166 & 7:16:24 PM & 0 & Merah & \\
\hline 167 & $7: 16: 25$ PM & 0 & Merah & \\
\hline 168 & 7:16:26 PM & 0 & Hijau & \\
\hline
\end{tabular}

Gambar 16 Tabel pada database

Pada gambar terlihat gambar tabel berisi data nomor, waktu pengambilan data, besar kecepatan dalam satuan rpm, dan hasil pembacaan sensor warna hasil pembacaan tersebut akan terekam dan masuk ke database yang terletak di file Microsoft Access.

d) Simulasi kerusakan dan maintenance

Berikut adalah tampilan pada layer HMI ketika mendeteksi kerusakan pada alat yakni motor DC di non-aktifkan sehingga HMI tidak mendapatkan sinyal pantul yang menandakan motor DC konveyor aktif, sehingga indikato alarm pada HMI akan menyala merah berkedip serta terdapat bunyi alarm peringatan. Hal ini akan membuat perhatian pada pengguna agar segera memberitahu agar dapat segera diperbaiki.

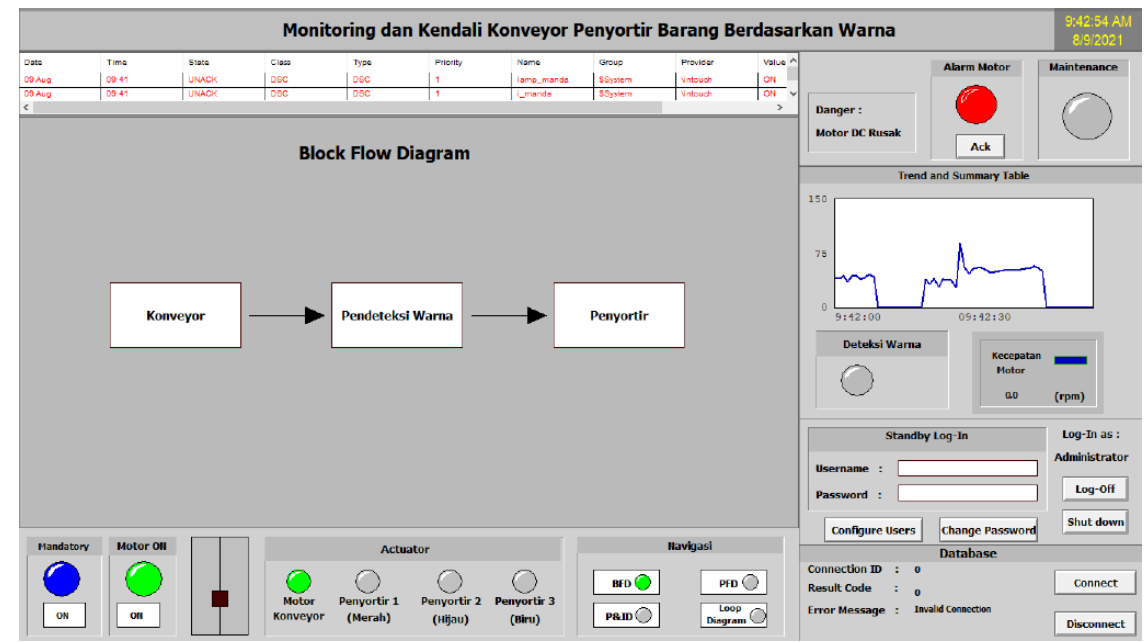

Gambar 17 Tampilan HMI ketika terdapat kerusakan

Kemudian gambar dibawah ini menunjukkan tampilan halaman HMI ketika kondisi plant sedang dilakukan perbaikan / maintenance. Sehingga terdapat indikator berwarna oranye sebagai tanda pemberitahuan kepada pengguna bahwa sedang ada perbaikan pada plant. 


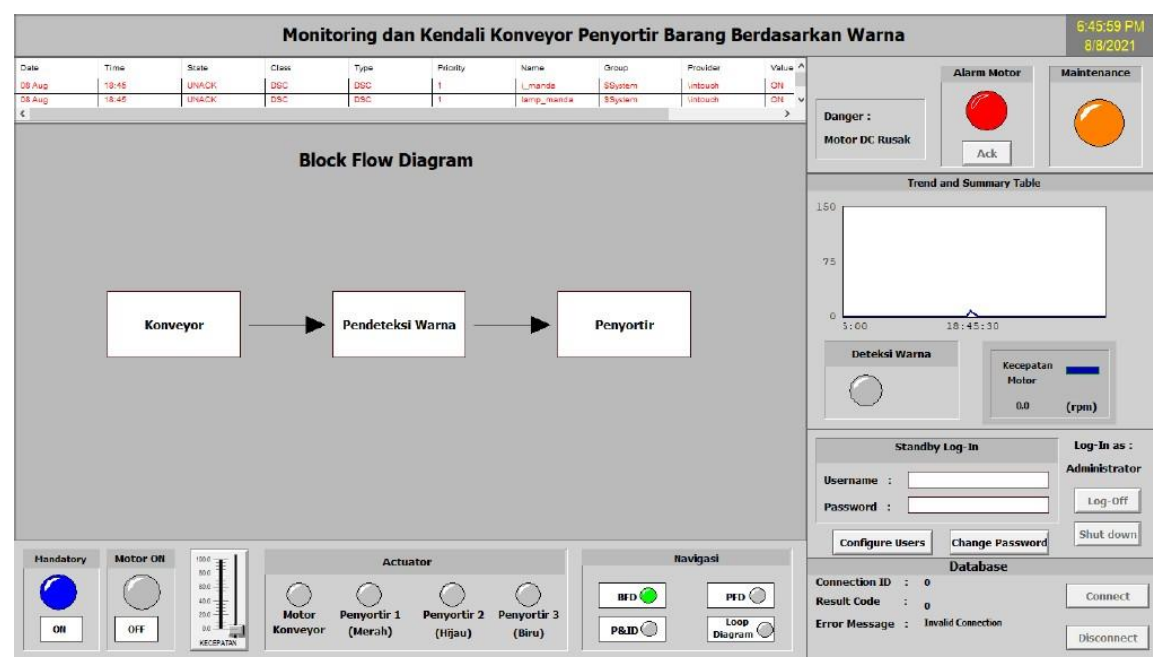

Gambar 18 Tampilan halaman HMI ketika kondisi maintenance

\section{Kesimpulan}

Berdasarkan hasil perancangan alat penyortir barang berdasarkan warna berbasis SCADA ini dapat disimpulkan bahwa secara keseluruhan memiliki bagian input yakni sensor warna TCS3200, bagian pusat pengolahan yakni Arduino Mega Pro 2560, bagaian output yakni motor DC 12V untuk konveyor serta motor servo SG90 sebagai lengan untuk menyortir barang yang warnanya telah terdeteksi sesuai dengan warna merah, hijau dan biru. Dilengkapi dengan HMI SCADA yang akan memonitoring dan mengendalikan kinerja plant sehingga dapat berjalan dengan baik. Hasil yang didapatkan sudah sesuai dengan tujuan yakni kecepatan putaran konveyor dapat diatur oleh HMI dengan slider, kemudian benda yang terdeteksi oleh sensor warna akan dipilah oleh lengan dan seluruh data pada HMI akan masuk ke dalam database mulai dari waktu pengambilan data, besar kecepatan konveyor dalam rpm, dan data warna hasil dari pendeteksian. 
Idries Syach, Yumna Salma Azzahra, dan Sandra Rayhan Seftia

\section{Bibliografi}

Adams, T. (2004). Supervisory Control and Data Acquisition (SCADA) Systems. National Communications System.

Fikri, Afrizal, Susana, Ratna, \& Nataliana, Decy. (2014). Monitoring Model Sistem Pengepakan dan Penyortiran Barang Berbasis SCADA. REKA ELKOMIKA, 2(4).

Husni, N. L., Rasyad, S., Hasan, Y., \& Al Rasyid, J. (2019). Pengaplikasian Sensor Warna Pada Navigasi Line Tracking Robot Sampah Berbasis Mikrokontroler. Jurnal Ampere, 4(2), 297-306.

Larasati, Sri. (2018). Manajemen Sumber Daya Manusia. Deepublish.

Pangestu, Aradea Putra, Ramdhani, Mohamad, \& Nugraha, Ramdhan. (2016). Perancangan Dan Implementasi Sistem Kendali Lengan Robot Penyortir Barang Berdasarkan Warna. EProceedings of Engineering, 3(3).

Rasyid, Renhat Baathinnur Aliyazhim. (2018). TA: Rancang Bangun Lengan Robot Pemilah Paket Barang Otomatis Berbasis Radio Frequency Identification (RFID). Universitas Dinamika.

Rif'an, Muhammad. (2012). RANCANG BANGUN HMI SCADA DENGAN DELPHI. PT Lestari Kiranatama.

Sari, Marlindia Ike, Handayani, Rini, Siregar, Simon, \& Isnu, Bagus. (2018). Pemilah Benda Berdasarkan Warna Menggunakan Sensor Warna TCS3200. TELKA-Jurnal Telekomunikasi, Elektronika, Komputasi Dan Kontrol, 4(2), 85-90.

Setianto, Ivan Dharmawan. (2018). Perancangan Komunikasi Dari Sistem Monitoring Pada Automation Sorting Line System. Institut Teknologi Sepuluh Nopember.

STEVEEN, BRYAN. (2018). Aplikasi Sistem Monitoring Pada Rancang Bangun Penyortir Barang Berwarna Merah Dan Hijau Dengan HMI Berbasis PLC Schneider. undip. 